\title{
Comparative Analysis of Morphometric Characteristics of Scorpaenidae and Gobioninae
}

\author{
${ }^{\dagger}$ In-Seok Park ${ }^{1}$, Hyun Woo Gil ${ }^{1}$, Ji Su Oh${ }^{1}$, Hui Jung Choi ${ }^{2}$ and Chi Hong Kim ${ }^{3}$ \\ ${ }^{I}$ Division of Marine Bioscience, College of Ocean Science and Technology, \\ Korea Maritime and Ocean University, Busan 606-791, Korea \\ ${ }^{2}$ Marine Living Resources Research Division, KORDI, Ansan 426-744, Korea \\ ${ }^{3}$ Central Inland Fishes Research Institute, NFRDI, Gyeonggi-Do 477-815, Korea
}

\begin{abstract}
Measurements of closely related sets of classical and truss dimensions were analyzed to discriminate species of scorpaenidae including the dark banded rockfish, Sebastes inermis, the black rockfish, S. schlegeli, and gobioninae including the striped shiner, Pungtungia herzi, and the slender shiner, Pseudopungtungia tenuicorpa. The measurements of the dimensions were arc sin square root transformed, and compared as a function of the standard length of each species for statistical analysis. For values of the classical dimensions of the rockfish, 6 were greater for the dark banded rockfish than for the black rockfish, 1 value was smaller for the former, and for 2 values there was no statistically significant difference $(P>$ 0.05). For values of the classical dimensions of the shiners, 9 values were greater for the striped shiner than for the slender shiner, 2 values were smaller for the former, and for 1 value there was no statistically significant difference $(P>0.01)$. For values of the truss dimensions of the rockfish, 6 were greater for the dark banded rockfish than for the black rockfish, 1 was smaller for the former, and for 4 values there was no statistically significant difference $(P>0.05)$. For values of the truss dimensions of the shiners, 13 values were greater for the striped shiner than for the slender shiner, 3 values were smaller for the former, and for 6 values there was no statistically significant difference $(P>0.01)$. The dimension sets used in this study may be useful as taxonomic indicators for discriminating among fish species in Korea.

Key words : Classical dimension, Pungtungia herzi, Pseudopungtungia tenuicorpa, Sebastes inermis, S. schlegeli, Truss dimension
\end{abstract}

\section{INTRODUCTION}

Morphological differences based on general body type or unusual anatomical forms have been used to distinguish and compare among species and groups (Straüss \& Bond, 1990). Both truss (Straüss \& Bookstein, 1982) and classical (Hubbs \& Lagler, 1947) dimensions have been used to describe fish body shape. Classical dimensions are the most used in studies of morphometric characteristics of fish
(Straüss \& Bond, 1990; Park et al., 2001a, 2004, 2007). Truss dimensions, which include components of body depth and length along the longitudinal axis, have theoretical advantages over classical morphometric characters in discriminating among groups (Humphries et al., 1981; Straüss \& Bookstein, 1982; Winans, 1984; Currens et al., 1989; Park et al., 2001a, 2004).

Basic understanding of morphometric characteristics has been based on three aspects: (i) identifying unidentified

\footnotetext{
Manuscript received 20 April 2015, Received in revised form 11 May 2015, Accepted 22 May 2015

† Corresponding Author : In-Seok Park, Division of Marine Bioscience, College of Ocean Science and Technology, Korea Maritime and Ocean University, Busan 606-791, Korea. Tel. : +82-51-410-4321, Fax : +82-51-405-4322, E-mail : ispark@kmou.ac.kr

This is an Open Access article distributed under the terms of the Creative Commons Attribution Non-Commercial License (http:// creativecommons.org/licenses/by-nc/3.0) which permits unrestricted non-commercial use, distribution, and reproduction in any medium, provided the original work is properly cited.
} 
taxa such as unknown hybrids, and distinguishing sexes or species; (ii) investigating mutated forms of groups and species; and (iii) identifying and classifying biotypic associations (Straüss, 1985; Winans, 1985; Taylor et al., 1986; Park et al., 1997, 2001a, 2001b, 2003, 2004, 2006a, 2006b).

Taxonomically, the dark banded rockfish, Sebastes inermis belongs to the Scorpaeniformes (family Scorpaenidae) and is an ovoviviparous teleost. It is distributed throughout the seas of Korea and Southern Hokkaido (Japan) (Jung, 1977; Choi et al., 2002). It is an economically important species in coastal environments and is also reared in aquaculture. As dark banded rockfish is abundant it is possible to collect the fish throughout the year on the Southern coast of Korea, and it is a promising species for resources enhancement, including marine ranching (Jung, 1977; Lee \& Kim, 1992).

The black rockfish, S. schlegeli is also ovoviviparous and a member of the Scorpaenidae, and is distributed throughout the Korea, Japan, China and Yellow seas; in Korean waters it is a resident coastal fish (Jung, 1977; National Fisheries Research \& Development Agency, 1994). The black rockfish occurs throughout winter in all coastal waters of Korea because it is large, exhibits rapid growth amongst rockfish types, and is resilient to low temperatures. It is thus an appropriate target species for aquaculture and marine ranching (Park et al., 2004).

The striped shiner, Pungtungia herzi is a far eastern freshwater species belonging to the Cypriniformes (family Gobioninae), and is widely distributed throughout Korea, China, and Japan. The slender shiner, Pseudopungtungia tenuicorpa has the same taxonomic affiliation, but is an endemic Korean species restricted to the Han and Imjin rivers (Kim \& Park, 2002).

Basic ichthyological and biosystematics studies of the two rockfish species have been reported. Lee \& Kim (1992) and Park et al. (2012) reported reproduction and embryonic development, early growth and eye development of dark banded rockfish. In addition, microstructural growth of larval black rockfish was reported in 2000 (Lee \& Kim, 2000). Comparative study of striped shiner and slender shiner has been made of their phylogenetic relationships, based on urohyal characters (Kim \& Kang, 1989). However, detailed comparative morphological studies of the striped and slender shiner have not been conducted. Dark banded rockfish and black rockfish are one of seawater fish inhabited widely, and are breeding widely in Korea (Lee \& Kim, 1992). In addition, external morphology of two rockfish is similar, so that need to research two rockfish (Lee \& Kim, 2000; Park et al., 2012). Striped shiner and slender shiner are one of freshwater fish inhabited widely, and differences of morphometric characteristic between striped shiner and slender shiner are not shown nearly (Kim \& Kang, 1989). Therefore, in this study we investigated and compared the morphological features of these species in Korea, using both classical and truss dimensions. The objectives were to identify those morphometric characteristics that differ significantly between the two Scorpaenidae species, and to assess the origin of the two shiner species.

\section{MATERIALS AND METHODS}

\section{Experimental fish}

Dark banded rockfish, Sebastes inermis and black rockfish, S. schlegeli were reared and maintained at the Fishery Genetics \& Breeding Science Laboratory, Korea Maritime and Ocean University (KMOU), Korea. The rockfish were reared in 1100 L FRP circular culture tanks $(118 \mathrm{~cm}$ diameter, $101 \mathrm{~cm}$ height), each of which contained 50 fish. During rearing the dissolved oxygen concentration was $\geq 9.7 \mathrm{~mL} / \mathrm{L}$, the $\mathrm{pH}$ was $7.52-8.32$, and the water temperature was maintained at $20.5 \pm 0.5^{\circ} \mathrm{C}$. The fish were fed twice daily with extruded flounder pellets (type EP, Jeil Feed, Korea).

Specimens of striped shiner, Pungtungia herzi and slender shiner, Pseudopungtungia tenuicorpa were collected in July 
2010 from a headwater tributary of the Imjin River (Jinsang-

ri, Gunnam-myeon, Yeonchen-gun, Gyenggi-do, Korea), which discharges into Soyang Lake, and from Bukcheon (Buk-meon, Inje-gun, Gangweon-do, Korea). Specimens were also reared at the Fishery Genetics \& Breeding Science Laboratory, KMOU, Korea. Most samples were randomly collected by trapping and hand netting. And digital pictures were taken for selected samples of each species using copystand and a Nikon D80 camera (D80, Nikon, Japan; Figs. 3 and 4).

\section{Measurement of morphometric characteristics}

Fish feeding was halted one day prior to morphometric analysis. Fifty fish of each species were collected and anaesthetized with a mixture of 500 ppm lidocaine- $\mathrm{HCl}$ (Hongseong Pharmaceuticals, Korea) and 1,000 ppm $\mathrm{NaHCO}_{3}$ (Sigma, USA), following the method of Park et al. (2004). The morphometric characteristics (including both classical and truss dimensions) used in an experiments concerning starvation in the Chinese minnow, Rhynchocypris oxycephalus, were applied in the morphometric analysis in the present study (Park et al., 2001a, 2004). As shown in Figs. 1 and 2, the morphometric characteristics of each species were measured to the nearest $1.0 \mathrm{~mm}, 0.1 \mathrm{~mm}$ using a digital vernier caliper (CD-20CP, Mitutoyo, Japan), respectively.

Table 1. Body shape dimensions for the dark banded rockfish, Sebastes inermis and the black rockfish, S. schlegeli

\begin{tabular}{|c|c|}
\hline $\begin{array}{l}\text { Standard length } \\
\text { Eye diameter }\end{array}$ & $\begin{array}{l}\text { Ls } \\
\text { ED }\end{array}$ \\
\hline \multicolumn{2}{|l|}{ Classical dimension } \\
\hline Direct distance between the anterior edge of the upper lip and the posterior end of supraoccipital & DALPS \\
\hline Direct distance between the anterior edge of the upper lip and the anterior insertion of the dorsal fin & DALAD \\
\hline Direct distance between the anterior edge of the upper lip and the margin of opercular cover & DALMO \\
\hline Direct distance between the anterior edge of the upper lip and the posterior insertion of the dorsal fin & DALPD \\
\hline Direct distance between the anterior edge of the upper lip and the base of pectoral fin & DALBP \\
\hline Direct distance between the anterior edge of the upper lip and the anterior insertion of the ventral fin & DALAV \\
\hline Direct distance between the anterior edge of the upper lip and the posterior insertion of the anal fin & DALPA \\
\hline Direct distance between the anterior edge of the upper lip and the anterior insertion of the anal fin & DALAA \\
\hline Caudal peduncle height & $\mathrm{CH}$ \\
\hline
\end{tabular}

\section{Truss dimension}

Direct distance between the anterior edge of the upper lip and the posterior end of supraoccipital

DALPS

Direct distance between the posterior end of suparoccipital and the margin of opercular cover

DPSMO

Direct distance between the anterior insertion of the dorsal fin and the posterior insertion of the dorsal fin

DADPD

Direct distance between the anterior insertion of the dorsal fin and posterior insertion of the anal fin

DADPA

Direct distance between the anterior insertion of the dorsal fin and the anterior insertion of the anal fin

DADAA

Direct distance between the anterior insertion of the ventral fin and the anterior insertion of the anal fin

DAVAA

Direct distance between the anterior insertion of the ventral fin and the posterior insertion of the dorsal fin

DAVPD

Direct distance between the anterior insertion of the anal fin and the posterior insertion of the anal fin

DAAPA

Direct distance between the anterior insertion of the anal fin and the posterior insertion of the dorsal fin

DAAPD

Direct distance between the posterior insertion of the dorsal fin and the posterior insertion of the anal fin

DPDPA 
Nine classical dimensions were measured for the rockfish species (DALPS, DALAD, DALAA, DALAV, DALMO, DALPD, DALBP, DALPA, and CH), while for the shiner species 12 measurements were made (DALPS, DALAD, DALAA, DALAV, DALMO, DALDC, DALAP, DALPM, DADAV, DPDPL, CH, and DPLPA) (Tables 1 and 2; Figs. $1 \mathrm{a}$ and $2 \mathrm{a})$.

Eleven truss dimensions were measured for the rockfish species (DALPS, DPSMO, DADPD, DADPA, DADAA, DAVAA, DAVPD, DAAPA, DAAPD, DPDPA, and CH), while for the shiner species 22 measurements were made (DALPS, DALPM, DPSAD, DPSAV, DPSAP, DPSPM, DADPD, DADAA, DADAV, DADAP, DPDDC, DPDVC, DPDPA, DAAPD, DAVPD, CH, DDCPA, DVCPA, DAAPA, DAVAA, DAVAP, and DAPPM) (Tables 1 and 2; Figs. $1 \mathrm{~b}$ and $2 \mathrm{~b}$ ). In addition, the standard length (Ls) was measured for each species (Tables 1 and 2; Figs. 1 and 2), and the eye diameter (ED) was measured for the rockfish species (Table 1; Fig. 1).

\section{Statistical analysis}

Data on the morphometric traits of each species were arc sin square root transformed, and analyzed relative to the standard length (Ls) of each species (Park et al., 2001a, 2001b, 2007). To assess the statistical significance of differences in measurements and average values of each parameter we used a one-way ANOVA (SPSS 9.0, SPSS Inc., USA). We used Duncan's multiple range test $(P<0.05)$ for the rockfish species, and for the shiner species the Sidak pairwise test was used for multiple comparisons; differences between means were regarded as significant at $P<0.01$.

\section{RESULTS AND DISCUSSION}

The average Ls was $13.6 \pm 1.05 \mathrm{~cm}$ for dark banded rockfish, Sebastes inermis, $14.9 \pm 1.31 \mathrm{~cm}$ for black rockfish, S. schlegeli, $68.2 \pm 4.34 \mathrm{~cm}$ for striped shiner, Pungtungia herzi, and $53.1 \pm 3.56 \mathrm{~cm}$ for slender shiner Pseudopungtungia tenuicorpa,

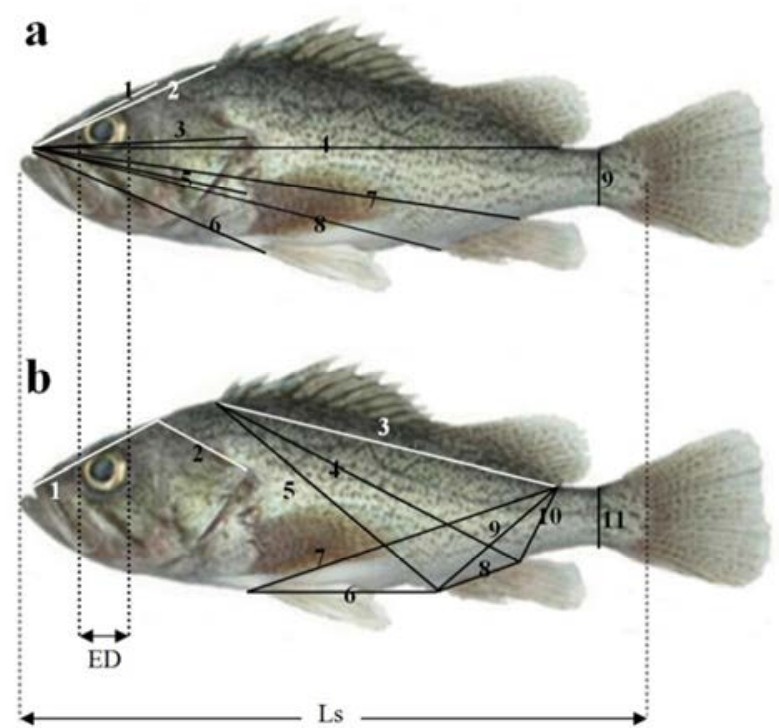

Fig. 1. Truss and classical dimensions measured for the dark banded rockfish, Sebastes inermis and the black rockfish, $\boldsymbol{S}$. schlegeli. (a) classical dimensions: 1, DALPS; 2, DALAD; 3, DALMO; 4, DALPD; 5, DALBP; 6, DALAV; 7, DALPA; 8, DALAA; 9, CH. (b) truss dimensions: 1, DALPS; 2, DPSMO; 3, DADPD; 4, DADPA; 5, DADAA; 6, DAVAA; 7, DAVPD; 8, DAAPA; 9, DAAPD; 10, DPDPA; 11, $\mathrm{CH}$. Refer to Table 1 for details of the dimensions.

respectively. The comparative results for the Ls and the classical and truss dimensions for all species are shown in Tables 3 and 4.

The measured values of the classical dimensions DALPS/ Ls, DALAD/Ls, DALPD/Ls, DALAV/Ls and DALPA/Ls for the dark banded rockfish were larger than those for the black rockfish. The value of dark banded rockfish for classical dimension (namely measurement items of body length based on body axis) was larger than that of black rockfish of body (Table 3; Fig. 3). There was no significant difference between dark banded rockfish and black rockfish for the classical traits DALBP and DALAA (from the premaxilla to the basal area of the pectoral fin and the start of the base of the anal fin, respectively; Table 3; Fig. 3) ( $P$ $>0.05)$. The results for measurement of classical dimensions in the two shiner species are shown in Table 4. The values of DALPS/Ls, DALAD/Ls, DALDC/Ls, DALAA/Ls, DALAV/ 
Table 2. Body shape dimensions for the striped shiner, Pungtungia herzi and the slender shiner, Pseudopungtungia tenuicorpa

\begin{tabular}{lc}
\hline \hline & \multicolumn{1}{c}{ Standard length } \\
\hline \multicolumn{1}{c}{ Classical dimension } & Ls \\
\hline $\begin{array}{l}\text { Direct distance between the anterior edge of the upper lip and the posterior end of supraoccipital } \\
\text { Direct distance between the anterior edge of the upper lip and the anterior insertion of the dorsal fin }\end{array}$ & DALPS \\
$\begin{array}{l}\text { Direct distance between the anterior edge of the upper lip and the dorsal origin of caudal fin } \\
\text { Direct distance between the anterior edge of the upper lip and the anterior insertion of the anal fin }\end{array}$ & DALAD \\
$\begin{array}{l}\text { Direct distance between the anterior edge of the upper lip and the anterior insertion of the ventral fin } \\
\text { Direct distance between the anterior edge of the upper lip and the anterior insertion of the pectoral fin }\end{array}$ & DALAV \\
$\begin{array}{l}\text { Direct distance between the anterior edge of the upper lip and the posterior end of maxillary } \\
\text { Direct distance between the anterior edge of the upper lip and the margin of opercular cover }\end{array}$ & DALPM \\
$\begin{array}{l}\text { Direct distance between the anterior insertion of the dorsal fin and the anterior insertion of the ventral fin } \\
\text { Direct distance between the posterior insertion of the dorsal fin and the most posterior scale in lateral line }\end{array}$ & DADAV \\
Caudal peduncle height & DPDP \\
Direct distance between the most posterior scale in lateral line and the posterior insertion of anal fin & CH
\end{tabular}

Truss dimension

Direct distance between the anterior edge of the upper lip and the posterior end of supraoccipital DALPS

Direct distance between the anterior edge of the upper lip and the posterior end of maxillary DALPM

Direct distance between the posterior end of supraoccipital and the anterior insertion of the dorsal fin DPSD

Direct distance between the posterior end of supraoccipital and the anterior insertion of the ventral fin DPSAV

Direct distance between the posterior end of supraoccipital and the anterior insertion of the pectoral fin DPSAP

Direct distance between the posterior end of supraoccipital and the posterior end of maxillary DPSPM

Direct distance between the anterior insertion of the dorsal fin and the posterior insertion of the dorsal fin DADPD

Direct distance between the anterior insertion of the dorsal fin and the anterior insertion of the anal fin DADAA

Direct distance between the anterior insertion of the dorsal fin and the anterior insertion of the ventral fin DADAV

Direct distance between the anterior insertion of the dorsal fin and the anterior insertion of the pectoral fin DADAP

Direct distance between the posterior insertion of the dorsal fin and the dorsal origin of caudal fin DPDD

Direct distance between the posterior insertion of the dorsal fin and the ventral origin of caudal fin DPDVC

Direct distance between the posterior insertion of the dorsal fin and the posterior insertion of anal fin DPDA

Direct distance between the anterior insertion of the anal fin and the posterior insertion of the dorsal fin DAAPD

Direct distance between the anterior insertion of the ventral fin and the posterior insertion of the dorsal fin DAVPD

Caudal peduncle height

$\mathrm{CH}$

Direct distance between the dorsal origin of caudal fin and the posterior insertion of anal fin

DDCPA

Direct distance between the ventral origin of caudal fin and the posterior insertion of anal fin

DVCPA

Direct distance between the anterior insertion of the anal fin and the posterior insertion of anal fin

DAAPA

Direct distance between the anterior insertion of the ventral fin and the anterior insertion of the anal fin

DAVAA

Direct distance between the anterior insertion of the anal fin and the anterior insertion of the pectoral fin DAVAP

Direct distance between the anterior insertion of the pectoral fin and the posterior end of maxillary DAPPM 
Ls, DALAP/Ls, DALMO/Ls, DADAV/Ls, and CH/Ls were significantly greater for the striped shiner than the slender shiner $(P<0.01)$, whereas the opposite was found for the values of DPDPL/Ls and DPLPA/Ls. We found no significant difference between the values of DALPM/Ls between the two shiner species.

Some of the measured classical dimension were common to both the rockfish and shiners, (DALPS, DALAD, DALMO, DALAV, DALAA, and CH; Tables 1 and 2; Figs. 1a and 2a). As shown in Tables 3 and 4, the value of DALMO/Ls was significantly greater for the rockfish than the shiner, whereas the opposite was found for the values of DALAD/ Ls and DALAV/Ls. Thus, the length from the lip to the opecular cover was longer in rockfish than in shiner, and the lengths from the lip to the dorsal and ventral fins were longer in shiner than in rockfish (Figs 3 and 4). These results show that the body length relative to the head region is greater in shiners than rockfish. Classical dimensions have commonly been assessed in studies of the morphometric characteristics of fish bodies. These dimensions are focused on characteristics of the body length, depth, and width, and are mainly studied with respect to the anterior-posterior axis of the body, including the tail and head regions (Straüss \& Bond, 1990; Park et al., 2001a, 2004, 2007).

The DALPS/Ls and $\mathrm{CH}$ measurements were common to both the classical and truss dimensions, and their values for dark banded rockfish were greater than for black rockfish $(P$ $<0.05$; Table 3 ). As the $\mathrm{CH} / \mathrm{Ls}$ (caudal peduncle height) value for the dark banded rockfish is greater than that for the black rockfish, the upper side of the black rockfish from the dorsal fin to the caudal fin is curved slightly down (Fig. 3), while in the dark banded rockfish it is almost a straight line. The ED/Ls (head) value was greater $(12.4 \%)$ for the dark banded rockfish than for the black rockfish $(9.3 \%)(P<0.05)$. The DALMO/Ls and DPSMO/Ls values for the head in the dark banded rockfish $(35.1 \%$ and $17.4 \%$, respectively) were less than for the black rockfish

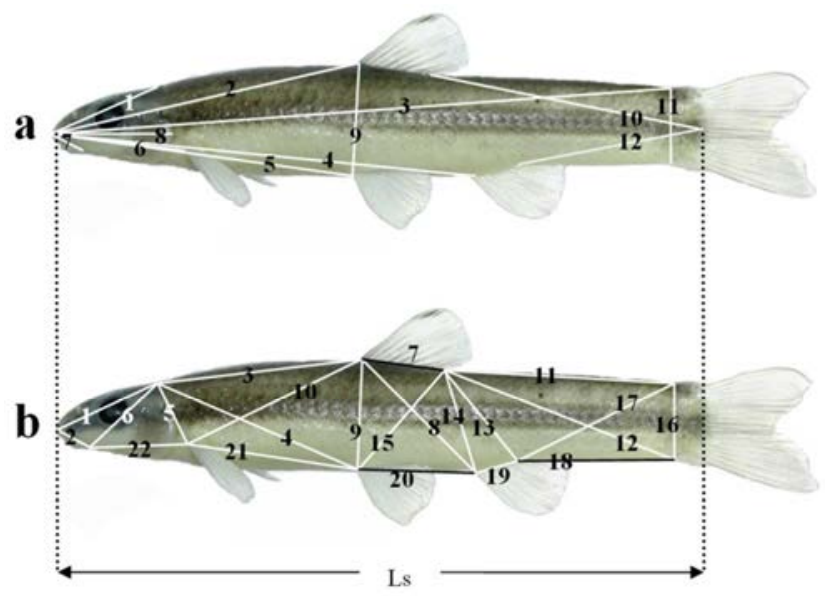

Fig. 2. Truss and classical dimensions measured for the striped shiner, Pungtungia herzi and the slender shiner, Pseudopungtungia tenuicorpa. (a) classical dimensions: 1, DALPS; 2, DALAD; 3, DALDC; 4, DALAA; 5, DALAV; 6, DALAP; 7, DALPM; 8, DALMO; 9, DADAV; 10, DPDPL; 11, CH; 12, DPLPA. (b) truss dimensions: 1, DALPS; 2, DALPM; 3, DPSAD; 4, DPSAV; 5, DPSAP; 6, DPSPM; 7, DADPD; 8, DADAA; 9, DADAV; 10, DADAP; 11 , DPDDC; 12, DPDVC; 13, DPDPA; 14, DAAPD; 15, DAVPD; 16, CH; 17, DDCPA; 18, DVCPA; 19, DAAPA; 20, DAVAA; 21, DAVAP; 22, DAPPM. Refer to Table 2 for details of the dimensions.

(36.5\% and 18.4\%, respectively) (Tables 2 and 3) $(P<$ $0.05)$. These results show that size of the eye as a function of head size is large in the dark banded rockfish relative to the black rockfish.

As shown in Table 3, the values of DALMO/Ls (classical dimension) and DPSMO/Ls (truss dimension) were greater for the black rockfish than for the dark banded rockfish $(P$ $<0.05)$. The length from the premaxilla to the end of the opercular of the operculum in the black rockfish was longer than in the dark banded rockfish (Fig. 3). In the shiners the truss and classical dimensions for most of the head and body region, and the caudal peduncle height, were significantly greater for the striped shiner, whereas measurements of the caudal region in relation to the anterior posterior body axis were significantly greater in the slender 
Table 3. Means and standard deviations of classical and truss dimensions for the dark banded rockfish, Sebastes inermis and the black rockfish, $S$. schlegeli, and the results of an ANOVA-test for differences among groups

\begin{tabular}{|c|c|c|c|}
\hline Morphometric dimension $^{\mathrm{a}}$ & Dark banded rockfish & Black rockfish & $t$ t-test \\
\hline \multicolumn{4}{|c|}{ Classical dimension } \\
\hline DALPS/Ls & $26.5 \pm 1.95$ & $21.2 \pm 1.73$ & $*$ \\
\hline DALAD/Ls & $36.8 \pm 1.20$ & $33.8 \pm 1.00$ & $*$ \\
\hline DALMO/Ls & $35.1 \pm 1.04$ & $36.5 \pm 1.03$ & $*$ \\
\hline DALPD/Ls & $90.9 \pm 1.21$ & $87.9 \pm 0.89$ & $*$ \\
\hline DALBP/Ls & $34.5 \pm 2.23$ & $35.3 \pm 0.76$ & NS \\
\hline DALAV/Ls & $41.7 \pm 0.94$ & $40.6 \pm 0.71$ & $*$ \\
\hline DALPA/Ls & $83.9 \pm 1.63$ & $82.7 \pm 1.23$ & $*$ \\
\hline DALAA/Ls & $69.0 \pm 1.86$ & $69.5 \pm 1.55$ & NS \\
\hline $\mathrm{CH} / \mathrm{Ls}$ & $11.6 \pm 0.49$ & $9.7 \pm 0.39$ & * \\
\hline $\mathrm{ED} / \mathrm{Ls}$ & $12.4 \pm 0.90$ & $9.3 \pm 0.51$ & * \\
\hline \multicolumn{4}{|c|}{ Truss dimension } \\
\hline DALPS/Ls & $26.5 \pm 1.95$ & $21.2 \pm 1.73$ & $*$ \\
\hline DPSMO/Ls & $17.4 \pm 1.31$ & $18.3 \pm 1.42$ & $*$ \\
\hline DADPD/Ls & $61.3 \pm 4.55$ & $60.2 \pm 1.61$ & NS \\
\hline DADPA/Ls & $58.5 \pm 1.57$ & $58.5 \pm 1.36$ & NS \\
\hline DADAA/Ls & $47.8 \pm 4.18$ & $49.4 \pm 1.18$ & NS \\
\hline DAVAA/Ls & $30.1 \pm 2.08$ & $31.4 \pm 1.53$ & NS \\
\hline DAVPD/Ls & $56.9 \pm 1.95$ & $54.0 \pm 1.17$ & * \\
\hline DAAPA/Ls & $18.7 \pm 1.31$ & $15.4 \pm 1.40$ & $*$ \\
\hline DAAPD/Ls & $30.9 \pm 1.19$ & $26.2 \pm 1.02$ & $*$ \\
\hline DPDPA/Ls & $15.0 \pm 0.63$ & $12.9 \pm 0.78$ & * \\
\hline $\mathrm{CH} / \mathrm{Ls}$ & $11.6 \pm 0.49$ & $9.7 \pm 0.39$ & * \\
\hline $\mathrm{ED} / \mathrm{Ls}$ & $12.4 \pm 0.90$ & $9.3 \pm 0.51$ & $*$ \\
\hline
\end{tabular}

\footnotetext{
${ }^{\mathrm{a}}$ Refer to Table 1 for details of dimensions. Data (means $\pm \mathrm{SD}, n=50$ ) were analyzed using a one-way ANOVA on data arcsine square root transformed. $* P<0.05$; NS: not significant.
}

shiner (Fig. 4). Similar to the results of this study, Park et al. (2004) investigated eye traits as head measurements is that clarify width between two eyes/distances between head length or premaxilla and two eyes/morphometrics of head length in catfish (Siluridae).

Katoh \& Tokimura (2001) compared measurements among the marbled rockfish, S. marmoratus, the red marbled rockfish, S. tertius, and the yellow barred red rockfish, S. albofasciatus, which are related to the two rockfish used in the present study. For these species the distance between the anterior upper jaw and the base of the dorsal fin differed, but no difference was found for the distance between the start of the base of the dorsal fin and the start of the base of the anal fin. In addition, they reported that the distance between the anterior upper jaw and the start of the base of the dorsal fin was greater in the marbled rockfish than in the 
red marbled rockfish. We found a similar trend in comparisons between the dark banded rockfish and the black rockfish.

Park et al. (2007) conducted a 12-week starvation experiment in olive flounder, Paralichthys olivaceus. In terms of truss dimensions, starvation in this predator resulted in a relative increase in body depth., while in terms of classical dimensions starvation resulted in a decrease in the values of traits related to the anterior-posterior axis of body, and an increase in the value of traits related to the head. Truss dimensions have also been applied to understanding the morphometric characteristics of Chinese minnow, Rhynchocypris oxycephalus in relation to starvation and predation. Under these conditions changes occurred in the characteristics of the body, rear body, and tail parts. It can identify whether various feed supply due to habitat difference and constant under head part is used as taxonomic indicators of Rhynchocypris sp. at starvation and predation experiment in Chinese minnow, inversely. As these fishes show variable measurements following habitat modification (especially starvation) and changes in nutritional status (such as food supplementation), it is essential to establish which morphometric characteristics in which species do not change as a function of variations in feed and environmental conditions (Park et al., 2001a, 2002, 2007).

Of those measurements for which the values were greater in the dark banded rockfish than in the black rockfish, the truss dimensions DAVPD/Ls, DAAPA/Ls, DAAPD/Ls, and DPDPA/Ls were largely related to the body depth from the start of the base of the ventral fin to the end of the base of the dorsal fin (Table 3; Fig. 3). The dark banded rockfish did not differ significantly from the black rockfish with respect to the measurement from the start of the base of the dorsal fin to the end of the base of dorsal fin of posterior body, the start of the base of the dorsal fin and the end of the base of the dorsal fin, and from the start of the base of the ventral fin to point for the base of the
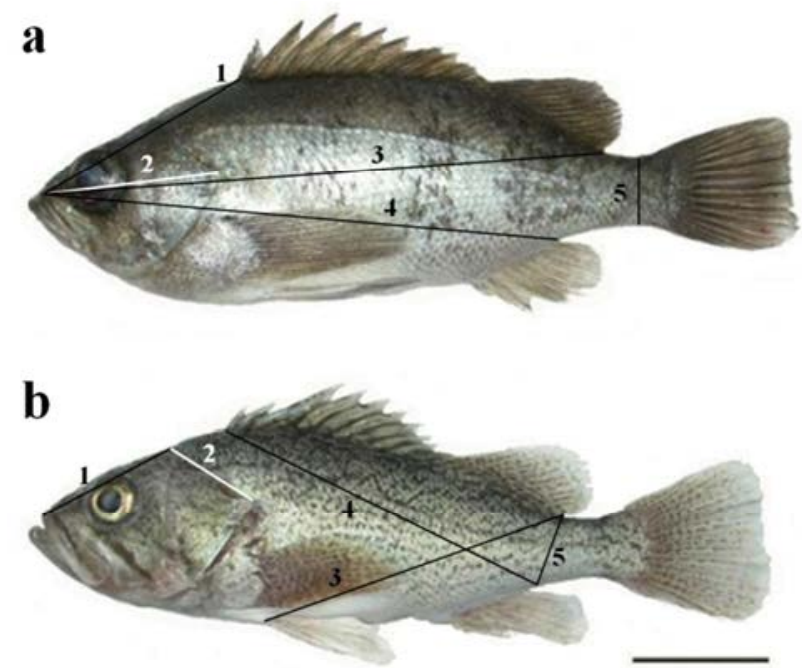

Fig. 3. External morphology of (a) the dark banded rockfish, Sebastes inermis and (b) the black rockfish, S. schlegeli. Lines of each picture are classical dimension and truss dimension having significantly difference $(P<0.05)$. (a) classical dimension: 1 , DALAD; 2, DALMO; 3, DALPD; 4, DALPA; 5, CH. (b) truss dimension: 1, DALPS; 2, DPSMO; 3, DAVPD; 4, DAAPD; 5, DPDPA. Black line: dark banded rockfish $>$ black rockfish; White line: dark banded rockfish $<$ black rockfish. Scale bar is $2 \mathrm{~cm}$.

caudal fin, as there were no significant differrences in truss dimensions between the dark banded rockfish and the black rockfish for the values of DADPD/Ls, DADPA/Ls, DADAA/ Ls, and DAVAA/Ls $(P>0.05)$ (Table 3; Fig. 3).

The truss dimensions for the two shiner species are shown in Table 4. Amongst these the values of DALPS/Ls, DPSAV/Ls, DPSAP/Ls, DPSPM/Ls, DADAA/Ls, DADAV/Ls, DADAP/Ls, DPDPA/Ls, DAAPD/Ls, DAVPD/Ls, CH/Ls, DAVAA/Ls, and DAPPM/Ls were significantly greater in the striped shiner than in the slender shiner $(P<0.01)$, the values for DPDDC/Ls, DDCPA/Ls, and DVCPA/Ls were significantly greater in the slender shiner $(P<0.01)$, and no significant difference was found between the species for the values of DALPM/Ls, DPSAD/Ls, DADPD/Ls, DPDVC/Ls, DAAPA/Ls, and DAVAP/Ls.

Comparing morphometric characteristics between dark 
Table 4. Classical and truss dimensions for the striped shiner, Pungtungia herzi and the slender shiner, Pseudopungtungia tenuicorpa

\begin{tabular}{|c|c|c|c|}
\hline Morphometric dimension $^{\mathrm{a}}$ & Striped shiner & Slender shiner & $t$-test \\
\hline \multicolumn{4}{|c|}{ Classical dimension } \\
\hline DALPS/Ls & $23.1 \pm 0.04$ & $19.2 \pm 0.02$ & $*$ \\
\hline DALAD/Ls & $52.2 \pm 0.01$ & $47.4 \pm 0.01$ & $*$ \\
\hline DALDC/Ls & $98.4 \pm 0.02$ & $94.9 \pm 0.03$ & $*$ \\
\hline DALAA/Ls & $71.8 \pm 0.02$ & $61.6 \pm 0.07$ & $*$ \\
\hline DALAV/Ls & $50.7 \pm 0.01$ & $46.2 \pm 0.01$ & $*$ \\
\hline DALAP/Ls & $25.4 \pm 0.02$ & $21.9 \pm 0.01$ & $*$ \\
\hline DALPM/Ls & $5.3 \pm 0.01$ & $5.4 \pm 0.01$ & NS \\
\hline DALMO/Ls & $25.3 \pm 0.02$ & $20.2 \pm 0.02$ & * \\
\hline DADAV/Ls & $22.8 \pm 0.01$ & $16.9 \pm 0.01$ & $*$ \\
\hline DPDPL/Ls & $38.2 \pm 0.02$ & $41.9 \pm 0.03$ & $*$ \\
\hline $\mathrm{CH} / \mathrm{Ls}$ & $13.0 \pm 0.01$ & $11.3 \pm 0.01$ & $*$ \\
\hline DPLPA/Ls & $23.3 \pm 0.01$ & $28.0 \pm 0.04$ & $*$ \\
\hline \multicolumn{4}{|c|}{ Truss dimension } \\
\hline DALPS/Ls & $23.1 \pm 0.01$ & $19.2 \pm 0.02$ & * \\
\hline DALPM/Ls & $5.3 \pm 0.01$ & $5.4 \pm 0.01$ & NS \\
\hline DPSAD/Ls & $31.3 \pm 0.01$ & $31.2 \pm 0.02$ & NS \\
\hline DPSAV/Ls & $34.9 \pm 0.01$ & $31.8 \pm 0.02$ & $*$ \\
\hline DPSAP/Ls & $13.4 \pm 0.01$ & $10.9 \pm 0.02$ & $*$ \\
\hline DPSPM/Ls & $18.6 \pm 0.01$ & $15.8 \pm 0.03$ & $*$ \\
\hline DADPD/Ls & $13.0 \pm 0.01$ & $12.6 \pm 0.01$ & NS \\
\hline DADAA/Ls & $29.6 \pm 0.01$ & $24.9 \pm 0.01$ & $*$ \\
\hline DADAV/Ls & $22.8 \pm 0.01$ & $16.9 \pm 0.01$ & $*$ \\
\hline DADAP/Ls & $30.6 \pm 0.01$ & $28.9 \pm 0.02$ & $*$ \\
\hline DPDDC/Ls & $34.0 \pm 0.01$ & $38.2 \pm 0.04$ & $*$ \\
\hline DPDVC/Ls & $36.7 \pm 0.01$ & $38.1 \pm 0.03$ & NS \\
\hline DPDPA/Ls & $22.0 \pm 0.01$ & $19.0 \pm 0.01$ & $*$ \\
\hline DAAPD/Ls & $19.8 \pm 0.01$ & $16.2 \pm 0.00$ & $*$ \\
\hline DAVPD/Ls & $23.1 \pm 0.01$ & $18.7 \pm 0.01$ & $*$ \\
\hline $\mathrm{CH} / \mathrm{Ls}$ & $13.0 \pm 0.01$ & $11.3 \pm 0.01$ & $*$ \\
\hline DDCPA/Ls & $23.4 \pm 0.01$ & $27.0 \pm 0.03$ & $*$ \\
\hline DVCPA/Ls & $18.7 \pm 0.02$ & $24.1 \pm 0.02$ & $*$ \\
\hline DAAPA/Ls & $6.2 \pm 0.01$ & $6.1 \pm 0.01$ & NS \\
\hline DAVAA/Ls & $21.5 \pm 0.02$ & $18.0 \pm 0.01$ & $*$ \\
\hline DAVAP/Ls & $25.5 \pm 0.01$ & $25.1 \pm 0.02$ & NS \\
\hline DAPPM/Ls & $20.6 \pm 0.01$ & $17.1 \pm 0.02$ & $*$ \\
\hline
\end{tabular}

\footnotetext{
${ }^{\text {a }}$ See Table 1 for details of dimensions. Data (means \pm SD, $n=50$ ) were analyzed using a one-way ANOVA on data arcsine square root transformed. $* P<0.01$; NS: not significant.
} 
banded rockfish and black rockfish, the classical dimensions DALAD, DALPD, DALPA and CH of dark banded rockfish were higher than those of black rockfish, and DALMO of dark banded rockfish was lower than black rockfish (Table 3 and Fig. 3a). The truss dimensions DALPS, DAVPD, DAAPD and DPDPA of dark banded rockfish were higher than black rockfish, and DPSMO of dark banded rockfish was lower than black rockfish (Table 3 and Fig. 3b). Comparing morphometric characteristics between striped shiner and slender shiner, the classical dimensions DALPS, DALAD and DALAA of striped shiner were higher than those of slender shiner, and DPDPL and DPLPA of striped shiner was lower than slender shiner (Table 4 and Fig. 4a). The truss dimensions DPSAV, DPSAP and DAVPD of striped shiner were higher than slender shiner, and DPDDC, DDCPA and DVCPA of striped shiner was lower than slender shiner (Table 4 and Fig. 4b).

The truss dimensions DALPS, PADPD, DADAA, DAVAA, DAVPD, DAAPA, DAAPD, DPDPA and $\mathrm{CH}$ were common to all species in the study (Tables 1 and 2; Figs. 1 and 2). As shown in Tables 3 and 4, the truss measurements DADPD/Ls, DADAA/Ls, DAVAA/Ls, DAVPD/Ls, DAAPA/Ls, and DAAPD/Ls were significantly greater in the rockfish than in the shiner, whereas the DPDPA/Ls value was significantly greater in the shiner than the rockfish. Thus, the lengths between the dorsal fins, from the dorsal fin to the ventral and anal fins, between the anal fins, and from the ventral to the anal fin were longer in the rockfish than in the shiner, whereas the vertical length of the tail region was longer in the shiner than in the rockfish (Figs. 3 and 4). These results indicate that shiners have an almost straight body line from head to tail, but rockfish have a relatively curved body shape. In addition, the rockfish generally had greater truss dimension values compared with the shiner (Tables 3 and 4), indicating that the body depth is greater in rockfish than in shiners.

Park et al. (2004) reported that for three truss dimensions
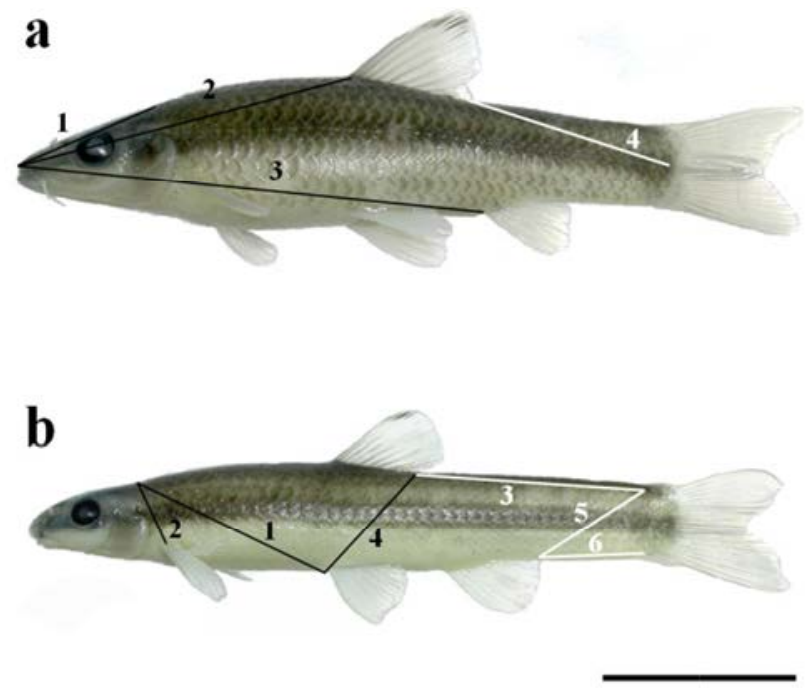

Fig. 4. External morphology of (a) the striped shiner, Pungtungia herzi and (b) the slender shiner, Pseudopungtungia tenuicorpa. Lines of each picture are classical dimension (a) and truss dimension (b) having significantly difference $(P<0.05)$. (a) classical dimension: 1, DALPS; 2, DALAD; 3, DALAA; 4, DPDPL; 5, DPLPA. (b) truss dimension: 1, DPSAV; 2, DPSAP; 3, DPDDC; 4, DAVPD; 5, DDCPA; 6, DVCPA. Black line: striped shiner $>$ slender shiner; White line: slender shiner $<$ striped shiner. Scale bar is $2 \mathrm{~cm}$.

the slender catfish, Silurus microdorsalis had greater values than the far eastern catfish, S. asotus. Park et al. (2006c) reported a similar finding for comparison of the bull-head torrent catfish, Liobagrus obesus and the Korean torrent catfish, $L$. andersoni with the yellow catfish, L. mediadiposalis. They suggested that truss dimensions are appropriate taxonomic indicators for discriminating among species of the Siluridae and the Amblycipitidae.

For more than 30 years, most morphometric investigations of fish have based character selection on the classical dimensions of length, depth, and width, primarily in the head and tail regions (Hubbs \& Lagler, 1947). These dimensions are concentrated along the anterior-posterior body axis and in the head-caudal regions, producing an uneven and biased coverage of the entire body form ( $\mathrm{Li}$ et al., 
1993). To describe the shape of a fish using a uniform network of distance measures, Humphries et al. (1981) suggested a criss-cross pattern along the body form, termed the truss dimensions.

In a comparison of rockfish, shiner and catfish, the anal fin and caudal peduncle height of striped shiner were greatest than the other species, but the ED of slender catfish and the head region of slender shiner were smallest (Park et al., 2004). In addition, the lengths between the lip and the dorsal fin, and between the lip and the ventral fin were significantly smaller in catfish relative to the other species, particularly shiner. Our results also indicate that certain truss or classical dimensions may be useful as taxonomic indicators for discriminating among species of rockfish and shiner. Furthermore, comparison with other species may be useful when similarities and differences are evident. In addition, caudal region dimensions (and some truss and classical dimensions that have been used as taxonomic indicators and in relation to embryology, ecology and physiology in salmonid fry, Chinese minnow and Far Eastern catfish, respectively) may also prove useful in discriminating among species of rockfish and shiner (Currens et al., 1989; Park et al., 2001a, 2004). Our findings illustrate that this set of truss dimensions facilitates the detection of differences in shape in oblique, longitudinal and vertical directions, as noted by Straüss \& Bond (1990).

The configuration of landmarks reconstructed from measured distances that result in no loss of information has advantages over the use of classical morphometric characters in discriminating in rockfish and shiner. Our results indicate that the use of the truss network as a character set enforces representative coverage across the body form, enhancing discrimination among species.

\section{ACKNOWLEDGEMENTS}

This research was funded through Project No. 20100021293 of the National Research Foundation of Korea,
Korea. We thank the members of the Inland Fisheries Ecological Research Institute (NFRDI) for assistance in collecting samples. Anonymous reviewers provided useful suggestions for improving the manuscript. All of the experiments performed in this study complied with the current laws of Korea (the Law Regarding Experimental Animals, No. 9932) and the Ethical Guidelines of Korea Maritime and Ocean University, Korea.

\section{REFERENCES}

Choi Y, Kim JH, Park JY (2002) Sea Fish in Korea. KyoHak Publishing Co., Seoul, Korea, p. 645.

Currens KP, Sharpe CS, Hjort R, Schreck CB, Li WH (1989) Effect of different feeding regimes on the morphometrics of chinook salmon (Oncorhynchus tshawtscha) and rainbow trout (O. mykiss). Copeia 3:689-695.

Hubbs CL, Lagler KF (1947) Fishes of the great lakes region. Cranbrook Inst Sci Bull 26:1-186.

Humphries JM, Bookstein FL, Chernoff B, Smith GR, Elder RL, Poss SC (1981) Multivarate discrimination by shape in relation to size. Syst Zool 30:291-308.

Jung MG (1977) The Fishes of Korea. Ilju Publish., Seoul, Korea, pp. 398-399.

Katoh M, Tokimura M (2001) Genetic and morphological identification of Sebastiscus tertius in the East China Sea (Scorpaeniformes: Scorpaenidae). Ichthyol Res 48: 247-255.

Kim IS, Kang EJ (1989) Comparative study on the urohyal of the subfamily Gobioninae of Korea. Korean J Ichthyol $1: 24-34$

Kim IS, Park JY (2002) Freshwater Fishes of Korea. KyoHak Publish. Co., Seoul, Korea, p. 465.

Lee TW, Kim GC (2000) Microstructural growth in otoliths of black rockfish, Sebastes schlegeli, from prenatal larval to early juvenile stages. Ichthyol Res 47:335-342.

Lee TY, Kim SY (1992) Reproduction and embryonic development within the maternal body of ovoviviparous 
teleost, Sebastes inermis. Fish Aquat Sci 25:413-431.

Li S, Cai W, Zhou B (1993) Variation in morphology and biochemical genetic markers among populations of blunt snout bream (Megalobrama amblycephala). Aquaculture 111: 117-127.

National Fisheries Research \& Development Agency. 1994. Commercial Fishes of the Coastal \& Offshore Waters in Korea. Yeamoonsa., Yangsan, Korea, p. 299.

Park I-S, Choi KC, Kim DS (1997) Production of hybrid and allotriploid between rainbow trout, Oncorhynchus mykiss and cherry salmon, O. masou П. Characteristics of sex ratio and morphometric traits. J Aquacult 10: 49-54.

Park I-S, Im JH, Ryu DK, Nam YK, Kim DS (2001a) Effect of starvation on morphometric changes in Rhynchocypris oxycephalus (Sauvage and Dabry). J Appl Ichthyol 17: 277-281.

Park I-S, Kim BS, Lee SJ, Hur JW, Yoo JS, Song YC, Kim YJ (2006a) Comparative morphometric traits of hybrids between red sea bream (Pagrus major) and black sea bream (Acanthopagrus schlegelii). J Fish Sci Technol 9:44-47.

Park I-S, Lim JH, Hur JW. (2004) Morphometric characteristics of catfish (Siluridae) in Korea. Korean J Ichthyol 16:223-228.

Park I-S, Lim JH, Jung CH, No JG, Kim YH, Lee YH (2002) Effect of starvation on some nutritional parameters in Rhynchocypris oxycephalus (Sauvage and Dabry). Korean J Ichthyol 14:11-18.

Park I-S, Nam YK, Douglas SE, Johnson SC, Kim DS (2003). Genetic characterization morphometrics and gonad development of induced interspecific hybrids between yellowtail flounder, Pleuronectes ferrugineus (Storer) and winter flounder, Pleuronectes americanus (walbaum). Aquacult Res 34:389-396.

Park I-S, Nam YK, Kim DS (2006b) Growth performance, morphometric traits and gonad development of induced reciprocal diploid and triploid hybrids between the mud loach (Misgurnus mizolepis Günther) and cyprinid loach (Misgurnus anguillicaudatus Cantor). Aquacult Res 37: 1246-1253.

Park I-S, Park HJ, Gil HW, Goo IB (2012) Early growth and characteristic of histological eye development in post parturition dark banded rockfish, Sebastes inermis. Dev Reprod 16:101-106.

Park I-S, Seol DW, Kang EJ, Kim CH (2006c) Morphometric characteristics of torrent catfish (Amblycipitidae) in Korea. Korean J Ichthyol 18:209-215.

Park I-S, Woo SR, Song YC, Cho SH (2007) Effects of starvation on morphometric characteristics of olive flounder, Paralichthys olivaceus. Ichthyol Res 54:297-302.

Park I-S, Zhang CI, Lee YD (2001b) Sexual dimorphism in morphometric characteristics of cocktail wrasse. J Fish Biol 58:1746-1749.

Straüss RE (1985). Evolutionary allometry and variation in body from in the South American catfish genus Corydoras (Callichthyidae). Syst Zool 34:81-396.

Straüss RE, Bond CE (1990) Taxonomic methods: morphology. In: Schreck CB, Moyle PB (eds.), Methods for Fish Biology, 1990. Amer Fish Soc., Bethesda, Maryland, U.S.A. 125-130.

Straüss RE, Bookstein FL (1982) The truss: Body from reconstructions in morphometrics. Syst Zool 31:113-135.

Taylor JN, Snyder DB, Courtenay WR Jr. (1986) Hybridization between two introduced, substrate-spawning tilapias (Pisces: Cichlidae) in Florida. Copeia 1986:903-909.

Winans GA (1984) Multivariate morphometric variability in Pacific salmon: Technical demonstration. Can J Fish Aquat Sci 41:1150-1159.

Winans GA (1985) Geographic variation in the milkfish (Chanos chanos). II. multivariate morphological evidence. Copeia 1985:890-898. 